\title{
Occult ischaemic necrosis of skeletal muscle associated with renal failure
}

\author{
J H Coakley, R H T Edwards, P McClelland, \\ J M Bone, T R Helliwell
}

University of Liverpool, L69 3BX

J H Coakley, MRCP, Englert clinical lecturer, muscle research centre

R H T Edwards, FRCP, professor of medicine

T R Helliwell, MRCPATH, senior lecturer, department of pathology

Regional Nephrology Unit, Royal Liverpool Hospital, Liverpool

P McClelland, MRCP, clinical research fellow

J M Bone, FRCP, consultant nephrologist

Correspondence to: Dr J H Coakley, Intensive Therapy Unit, St Bartholomew's Hospital, London EC1A 7BE.

BrMed f 1990;301:370
Acute renal failure associated with myoglobinuria may occur after traumatic and non-traumatic muscle damage. ${ }^{12}$ We report on three patients who developed acute renal failure with histological and biochemical evidence of muscle damage.

\section{Case reports}

Case 1-A 61 year old man developed thrombosis in a right femoropopliteal bypass graft necessitating below knee amputation. There were no muscle symptoms or signs and no loss of pulsation in the remaining leg. Twenty four hours postoperatively he became oliguric, acidotic, and hyperkalaemic. Serum creatine kinase activity was $>10000 \mathrm{U} / 1$ (normal $<190 \mathrm{U} / \mathrm{l}$ ). He developed oliguric renal failure, which was managed by haemofiltration for nine days and then haemodialysis for 28 days. Biopsy of the left anterior tibial muscle 14 days postoperatively showed necrosis of isolated muscle fibres (figure) with some regenerating fibres. He regained normal renal function.

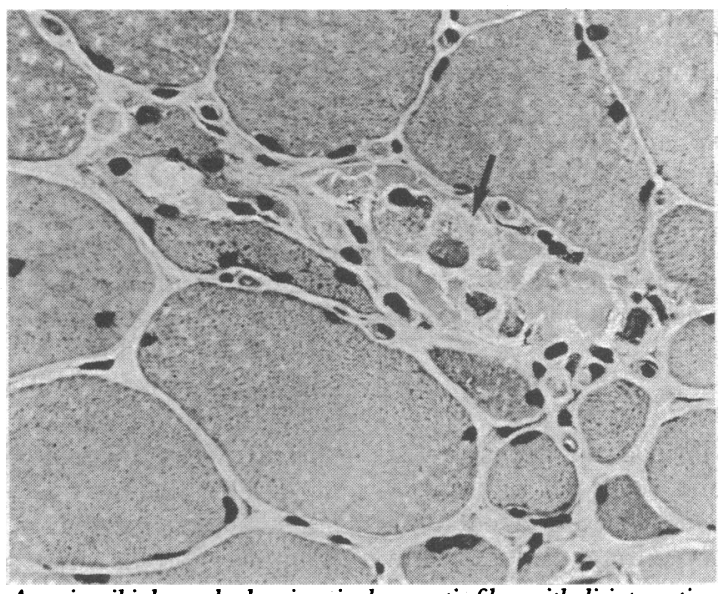

Anterior tibial muscle showing single necrotic fibre with disintegrating cytoplasm (arrowed). The necrotic fibre is surrounded by smaller regenerating fibres. (Haematoxylin and eosin)

Case 2-A 70 year old man underwent uneventful elective repair of an abdominal aortic aneurysm. Two days postoperatively he developed pallor and coldness of his legs without loss of peripheral pulses, which resolved spontaneously. Oliguria with rising plasma urea and potassium concentrations necessitated haemofiltration. He remained normotensive without evidence of sepsis. There was no muscle tenderness, and the weakness and wasting present 14 days later were thought to be related to his catabolic state. Biopsy of the anterior tibial muscle showed widespread infarction and loss of enzyme activity with some evidence of regeneration around small arteries. Serum creatine kinase activity was $>10000 \mathrm{U} / \mathrm{l}$. He died of bronchopneumonia with persistent renal failure 42 days after presentation.

Case 3-A 75 year old woman with maturity onset diabetes mellitus was admitted with chest pain and five days later developed acute oliguric renal failure. She required intermittent haemodialysis for six weeks before her renal function recovered. One episode of hypotension had occurred before she was transferred to the renal unit but there were no muscle symptoms or signs and no loss of arterial pulsation in the legs. Serial muscle enzyme activities were normal, but a muscle biopsy 17 days after her presentation showed no active necrosis but regenerating fibres, suggesting previous muscle damage. A renal biopsy after four weeks showed acute tubular necrosis with regenerating epithelium and pigmented casts in the tubules consistent with myoglobinuria. Her renal function recovered.

\section{Comment}

In these three patients renal failure was associated with histological evidence of muscle damage. Serum creatine kinase activity was raised in two. In many cases of acute renal failure the precise cause is difficult to establish with certainty, but we postulate that the degree of muscle necrosis suggested by the creatine kinase activity was sufficient to cause the renal failure in cases 1 and 2 . The necrosis was silent clinically and was proved only on muscle biopsy. In case 3 the histological findings suggested but were not diagnostic of muscle breakdown and myoglobinuria causing renal failure. We could not confirm the presence of myoglobinuria as the patients were referred to our unit with established renal failure, but we believe that the renal failure occurred when reperfusion of ischaemic muscle led to release of myoglobin. Myocardial reperfusion injury due to an influx of calcium may be prevented by prior administration of calcium channel blockers, ${ }^{3}$ but at the moment there is insufficient evidence to recommend their use for ischaemic skeletal muscle. Promoting diuresis with frusemide has shown no consistent benefit in experimental studies and may exacerbate renal failure. ${ }^{4}$

In certain circumstances early rehydration and treatment with mannitol produce osmotic diuresis and prevent intratubular obstruction by myoglobin before renal failure develops. Alkalising the urine may protect the kidney from myoglobin..$^{5}$ Often these measures are not feasible, but they could be considered during preoperative preparation for elective procedures.

Once renal failure is established it should be managed conventionally, although recovery may be protracted if muscle necrosis is widespread. If muscle biopsy had not been performed or serum muscle enzyme activity measured the muscle breakdown would not have been recognised. We suggest that in all cases of acute renal failure the possibility of muscle necrosis should be borne in mind.

We thank the Muscular Dystrophy Group of Great Britain and Northern Ireland for financial support.

1 Bywaters EGL, Beall D. Crush injuries with impairment of renal function. BrMed f 1941;i:427-32.

2 Grossman RA, Hamilton RW, Morse BM, Penn AS, Goldberg M. Nontraumatic rhabdomyolysis and acute renal failure. $N$ Engl F Med 1974;291 $807-11$.

3 Braunwald E. Mechanism of action of calcium channel blocking agents. NEngl f Med 1982;307:1618-27.

4 Bailey RR, Natale R, Turnbull DI, Linton AL. Protective effect of frusemide in Bailey RR, Natale R, Turnbull DI, Linton AL. Protective effect of frusenite tubular necrosis and acute renal failure. Clin Sci 1973;45:1-17.

5 Ron D, Taitelman U, Michaelson M, Bar-Joseph G, Bursztein S, Better OS. Prevention of acute renal failure in traumatic rhabdomyolysis. Arch Intern Med 1984;144:277-80.

(Accepted 25 May 1990) 